\title{
OnabotulinumtoxinA effectiveness on chronic migraine, negative emotional states and sleep quality: a single-center prospective cohort study
}

\author{
Elif Ilgaz Aydinlar, Pinar Yalinay Dikmen, Seda Kosak and Ayse Sagduyu Kocaman
}

\begin{abstract}
Background: OnabotulinumtoxinA (OnabotA) is considered effective in in patients with chronic migraine (CM) who failed on traditional therapies. This study was designed to evaluate the effect of OnabotA injection series on migraine outcome, negative emotional states and sleep quality in patients with CM.

Methods: A total of 190 patients with CM (mean (SD) age: 39.3 (10.2) years; 87.9\% were female) were included. Data on Pittsburgh sleep quality index (PSQI), headache frequency and severity, number of analgesics used, Migraine Disability Assessment Scale.

(MIDAS) scores and Depression, Anxiety and Stress Scale (DASS-21) were evaluated at baseline (visit 1) and 4 consecutive follow up visits, each conducted after OnabotA injection series; at week 12 (visit 2), week 24 (visit 3), week 36 (visit 4) and week 48 (visit 5) to evaluate change from baseline to follow up.

Results: From baseline to visit 5, significant decrease was noted in least square (LS) mean headache frequency (from 19.5 to $8.4, p=0.002$ ), headache severity (from 8.1 to $6.1, p=0.017$ ), number of analgesics (from 26.9 to 10.4, $p=0.023$ ) and MIDAS scores (from 67.3 to $18.5, p<0.001$ ). No significant change from baseline was noted in global PSOI and DASS-21 scores throughout the study.

Conclusions: Our findings revealed that OnabotA therapy was associated with significant improvement in migraine outcome leading to decrease in headache frequency and severity, number of analgesics used and MIDAS scores. While no significant change was noted in overall sleep quality and prevalence of negative emotional states, patients without negative emotional states at baseline showed improved sleep quality throughout the study.
\end{abstract}

Keywords: Chronic migraine, Sleep quality, Headache, Analgesic, MIDAS, DASS-21

\section{Background}

Chronic Migraine (CM) is a complex and severely disabling neurological disorder, characterized by occurrence of headache on $\geq 15$ days per month for $>3$ months with at least five attacks fulfilling criteria of migraine without aura on $\geq 8$ days per month [1].

Having a prevalence of $1-3 \%$ documented in population-based studies [2], CM is considered to be a more disabling and burdensome disorder than episodic migraine (EM), as associated with greater

\footnotetext{
* Correspondence: elif.aydinlar@acibadem.edu.tr

Department of Neurology, Acibadem University School of Medicine, Içerenkoy, Kayisdagi Cd, 34752 Atasehir/Istanbul, Turkey
}

migraine-related disability [3], more frequent hospital admissions [4-6], poorer health-related quality of life (HRQoL) [4-7], higher amount of lost work and household productivity $[4-6,8]$, and increased risk for comorbidities [9] and medication overuse [10].

Increased comorbidity between migraine and several psychiatric conditions has consistently been reported with higher prevalence of mood and anxiety disorders, personality disorders and post-traumatic stress disorder (PTSD) among migraineurs than in the general population [11-13]. Also, increased headache frequency was shown to be correlated with higher rate of depression, anxiety and post-traumatic stress disorder $[5,14-16]$. 
Recent studies also indicate a higher prevalence of poor sleep quality in patients with than without migraine and association of frequency of migraine headache with poor sleep quality [17-22].

This seems notable given the association of comorbidities with increased burden of $\mathrm{CM}$ in terms of productivity loss, impaired HRQoL, healthcare utilization and emotional burden ${ }^{5}$ as well as treatment complications and poor clinical outcomes [13].

Despite availability of preventive and abortive treatments as the mainstays of treatment for migraines, onethird of migraine sufferers remain symptomatic due to frequent partial response to treatment that leads to physical disability and high risk of medication overuse [22-24]. Therefore, development of new and effective therapeutic alternatives is of particular significance in the management of $\mathrm{CM}[24,25]$.

Onabotulinumtoxin A (OnabotA) recently was discovered to be effective in preventing recurrent migraines in patients with CM who failed on traditional therapies [22, 26, 27]. Hence, based on data from PREEMPT (Phase 3 REsearch Evaluating Migraine Prophylaxis Therapy) trials confirming its efficacy in reduction of number of headache days and migraine days in $\mathrm{CM}$ patients with favorable safety and tolerability [28-31], OnabotA (155-195 U) is specifically indicated as a prophylactic treatment for CM in adults [26, 32].

The present study was designed to evaluate the effect of OnabotA injection series on migraine outcome, negative emotional states and sleep quality in patients with $\mathrm{CM}$.

\section{Methods}

\section{Study population}

A total of 190 consecutive patients with CM (mean (SD) age: 39.3 (10.2) years; $87.9 \%$ were female) were included in this single-center prospective cohort study conducted between May 2012 and May 2016. After baseline visit at study enrollment (visit 1), patients were followed up for 48 weeks via 4 consecutive follow up visits each conducted after a new OnabotA injection series; at week 12 (visit 2), week 24 (visit 3), week 36 (visit 4) and week 48 (visit 5), respectively. Most of the patients had a history of prophylactic treatment for migraine which was either insufficient or was discontinued due to intolerance.

Written informed consent was obtained from each subject following a detailed explanation of the objectives and protocol of the study which was conducted in accordance with the ethical principles stated in the "Declaration of Helsinki" and approved by the Acibadem University Clinical Research Ethics Committee.

\section{Study parameters}

Data on patient demographics (age, gender), educational status, diagnosis ( $\mathrm{CM}, \mathrm{CM}+$ medication overuse), migraine duration (year), family history for migraine, previous migraine treatments, migraine triggers are collected at baseline visit (visit 1). Data on migraine outcome [headache frequency and severity, number of analgesics used and Migraine Disability Assessment Scale (MIDAS) scores], sleep quality [Pittsburgh sleep quality index (PSQI)] and negative emotional states [Depression, Anxiety, and Stress Scale-21 (DASS-21)] were evaluated at baseline and follow up visits. Medication overuse was baseline of simple analgesics on $\geq 15$ days. Follow up period was composed of 4 consecutive visits each conducted after a new OnabotA injection series; at week 12 (visit 2), week 24 (visit 3), week 36 (visit 4) and week 48 (visit 5), respectively. Change from baseline to follow up was evaluated based on data from visit 1 to visit 3 (24 weeks) for PSQI, from visit 1 to visit 4 (36 weeks) for DASS-21 scores, while based on data from visit 1 to visit 5 (48 weeks) for headache frequency and severity, number of analgesics used and MIDAS score. Data at visit 2 , visit 3, visit 4 and visit 5 refer to changes in parameters observed after $1^{\text {st }}, 2^{\text {nd }}, 3^{\text {rd }}$ and $4^{\text {th }}$ OnabotA injection series, respectively.

\section{Diagnosis of $\mathrm{CM}$}

$\mathrm{CM}$ was diagnosed based on International Classification of Headache Disorders (third revision) (ICHD-3 beta) diagnostic criteria that require headache occurring on $\geq 15$ days per month for $>3$ months with at least five attacks fulfilling criteria of migraine without aura on $\geq 8$ days per month [1].

\section{OnabotA injection series}

Administration of OnabotA was performed as 31 fixedsite, fixed-dose intramuscular injections applied at seven specified head and neck muscle points every 12 weeks for a minimum of 24 weeks ( 2 treatment cycles) according to injection scheme proposed in the PREEMPT studies $[28,29,33]$. We additionally administered OnabotA among occipitalis, temporalis or trapezius muscles using a follow-the-pain strategy.

\section{MIDAS}

The MIDAS is a 5-question tool to quantitatively evaluate the headache-related disability in terms of the number of days in the past 3 months and activity limitations due to migraine. MDAS was developed by Stewart et al.[34] and validated and checked for reliability for Turkish by Ertas et al. [35] The score obtained can be graded as follows: grade I ( 0 to 5 days) indicative of little or no disability; grade II (6 to 10 days), mild disability; grade III (11 to 20 days), moderate disability; and grade IV (greater than 21 days), severe disability. 


\section{DASS-21}

The DASS-21 is a 21-item questionnaire which includes three self-report scales designed to measure the negative emotional states of depression, anxiety and stress. The Depression scale includes items that measure symptoms typically associated with dysphoric mood (e.g., sadness or worthlessness). The Anxiety scale includes items that are primarily related to symptoms of physical arousal, panic attacks, and fear (e.g., trembling or faintness). Finally, the Stress scale includes items that measure symptoms such as tension, irritability, and a tendency to overreact to stressful event. Each item is scored on a 4point scale $(0=$ Did not apply to me at all, to $3=$ Applied to me very much or most of the time) to rate the extent to which they have experienced each state over the past week. Sum of the score of each item reveals the total score with higher scores indicating greater levels of distress. Each state is categorized into normal/mild/moderate/severe/extremely severe based on cut-off scores recommended for depression (0-4/5-6/7-10/11-13/14+), anxiety (0-3/4-5/6-7/8-9/10+) and stress (0-7/8-9/10-12/ 13-16/17+) [36-38]. Psychometric properties of the Turkish version of the DASS was studied by Hekimoglu et al. and DASS was shown to be an excellent instrument for measuring features of depression, hyperarousal, and tension in clinical groups [39].

\section{PSQI}

The PSQI, used to assess sleep quality, was developed by Buysse et al. [40] and validated and checked for reliability for Turkish by Agargun et al. [41]. The scale consists of 24 items; eighteen items are scored and yield seven component scores. Each component is scored between 0 and 3 and the total of these scores gives the scale score. The total score ranges between 0 and 21 and the higher the score is, the worse the sleep quality. A total score under 5 indicates 'good sleep quality', while a score above 5 shows 'poor sleep quality'.

\section{Statistical analysis}

Statistical analysis was made using IBM SPSS Statistics (IBM Corp. Released 2012. IBM SPSS Statistics for Windows, Version 21.0, Armonk, NY: IBM Corp). Change over time analysis was based on number of patients with available data on both baseline (visit 1) and follow-up visits (visit 2 to 5 ), and performed via repeated measures variance analysis and McNemar test for continuous and categorical variables, respectively. Since time to follow up visits showed variability among patients, change over time analysis of continuous variables were adjusted for time (visit $2=12$ weeks; visit $3=24$ weeks; visit $4=$ 36 weeks; visit $5=48$ weeks). No specific procedure was defined for missing data. Data were expressed as $n(\%)$, mean (standard deviation; SD), median (inter-quartile range, IQR) and mean (lower and upper boundaries of 95\% confidence interval; CI) where appropriate. $p<0.05$ was considered statistically significant.

\section{Results}

Patient disposition and baseline characteristics

Of 190 patients; 101 (53.2\%) attended at least one follow-up visit. Overall 98 (51.6\%) patients attended visit 2, $58(30.5 \%)$ patient visit 3, 34 (17.9\%) patients visit 4, and $20(10.5 \%)$ patients attend visit 5 , which were performed at week 12, week 24, week 36 and week 48, respectively.

During the study period overall four injection series were applied per patient within a total treatment time of 48 weeks (median (IQR) 62.4 (53.8-85.2) weeks).

Most of the participants were university graduates (41.1\%), diagnosed with CM per se $(48.9 \%)$ without triggers $(76.8 \%)$ and for median (IQR) 3.0 (1.0-10.0) years. Family history for migraine was evident in $28.9 \%$ of patients; while most common previous medication was non steroid anti-inflammatory drugs (88.4\%). Medication overuse was evident in $76.2 \%$ of patients (Table 1 ).

\section{Migraine outcome}

Overall, mean (SD; median) headache frequency was $17.9(7.8 ; 15.0)$ at visit 1 and $6.8(5.1 ; 5.0)$ at visit 5 . Median (IQR) headache severity scores were 8.0 (7.0-9.0) and 7.0 (5.0-7.0), number of analgesics used were 20.0 (15.0-30.0) and $5.5(2.0-10.0)$ and MIDAS scores were $57.0(35.5-75.0)$ and $10.0(2.0-15.0)$ at visit 1 and visit 5, respectively (Table 2 ).

Mean headache frequency was significantly decreased from LS mean 19.5 at visit 1 to 6.8 at visit $2(p<0.001)$, to 7.5 at visit $3(p<0.001)$, to 5.4 at visit $4(p<0.001)$ and to 8.4 at visit $5(p=0.002)$ (Table 3$)$.

Mean headache severity was significantly decreased from 8.1 at baseline to 6.2 at visit $2(p<0.001)$, to 5.8 at visit 3 and visit 4 ( $p<0.001$ for each) and to 6.1 at visit 5 $(p=0.017)$ (Table 3$)$.

Mean number of analgesics used was significantly decreased from 26.9 at baseline to 7.8 at visit $2(p<0.001)$, to 8.7 at visit $3(p<0.001)$, to 5.1 at visit $4(p<0.001)$ and to 10.4 at visit $5(p=0.023)$ (Table 3$)$.

Mean MIDAS score was decreased significantly from 67.3 at baseline to 17.4 at visit $2(p<0.001)$, to 15.3 at visit $3(p<0.001)$, to 9.3 at visit $4(p<0.001)$ and to 18.5 at visit $5(p<0.001)$ (Table 3$)$.

\section{Negative emotional states}

DASS-21 revealed normal scores for depression (60.0, 52.0, 60.0 and 57.1\%), anxiety (56.5, 51.5, 41.2 and $57.1 \%)$ and stress $(51.8,54.5,29.4$ and $42.9 \%)$ in similar percentage of patients at visit 1 , visit 2, visit 3 and visit 4 , respectively (Table 4). 
Table 1 Patient characteristics

\begin{tabular}{|c|c|}
\hline Age (year), mean (SD) & $39.3(10.2)$ \\
\hline \multicolumn{2}{|l|}{ Gender, n(\%) } \\
\hline Male & $23(12.1)$ \\
\hline Female & $167(87.9)$ \\
\hline Total & $190(100.0)$ \\
\hline \multicolumn{2}{|l|}{ Educational status, n(\%) } \\
\hline Primary school & $9(4.7)$ \\
\hline High school & $22(11.6)$ \\
\hline University & $78(41.1)$ \\
\hline $\mathrm{MSC} \& \mathrm{PhD}$ & $9(4.7)$ \\
\hline Missing & 72 \\
\hline \multicolumn{2}{|l|}{ Diagnosis n(\%) } \\
\hline Chronic migraine & $93(48.9)$ \\
\hline Chronic migraine + medication overuse & $97(51.1)$ \\
\hline Migraine duration (year), median (IQR) & $3.0(1.0-10.0)$ \\
\hline \multicolumn{2}{|l|}{ Family history for migraine, $\mathrm{n}(\%)$} \\
\hline Present & $55(28.9)$ \\
\hline Absent & $61(32.1)$ \\
\hline Missing & 74 \\
\hline \multicolumn{2}{|l|}{ Previous migraine treatments, n(\%) } \\
\hline Non-steroid anti-inflammatory drugs & $168(88.4)$ \\
\hline Antiepileptic & $61(32.1)$ \\
\hline Antidepressants & $57(30.0)$ \\
\hline Beta blockers & $24(12.6)$ \\
\hline Calcium channel blockers & $1(0.5)$ \\
\hline \multicolumn{2}{|l|}{ Migraine triggers, $\mathrm{n}(\%)$} \\
\hline None & $146(76.8)$ \\
\hline At least one trigger & $44(23.2)$ \\
\hline Air/weather change & $13(6.8)$ \\
\hline Anxiety/depression & $15(7.9)$ \\
\hline Fasting & $21(11.1)$ \\
\hline Food/beverage & $12(6.3)$ \\
\hline Insomnia & $33(17.4)$ \\
\hline Menstruation & $22(11.6)$ \\
\hline Stress & 35 (18.4) \\
\hline
\end{tabular}

IQR interquartile range

Mild-to-moderate depression (29.4\% at visit $1,28.6 \%$ at visit 4$)$, anxiety (25.9\% at visit $1,28.6 \%$ at visit 4$)$ and stress $(35.3 \%$ at visit $1,42.9 \%$ at visit 4 ) was evident in remarkable percentage of patients throughout the study period, while severe-to-extremely severe depression $(10.6 \%$ at visit $1,14.3 \%$ at visit 4$)$, anxiety $(17.7 \%$ at visit $1,14.3 \%$ at visit 4$)$ and stress $(12.9 \%$ at visit $1,14.3 \%$ at visit 4) were also noted in less than $15 \%$ of patients.

Based on patients with valid data for both baseline and follow up visits, no significant change was noted in percentage of patients categorized to have normal anxiety, depression and stress scores at each follow up visit (Table 5).

\section{Sleep quality}

Overall, median (IQR) global score at visit 1 and visit 5 were $9.0(5.0-12.0)$ and 4.0 (1.0-7.0), respectively (Table 6).

Based on patients with valid data for both baseline and follow up visits, no significant difference was noted in global scores and thus overall sleep quality from baseline to visit 2 or visit 3. Considering component scores, mean (95\% CI lower bound-upper bound) scores for subjective sleep quality (from baseline 1.7 (1.4-2.0) to $1.1(0.8-1.5)$ at visit $2, p=0.002$ ), sleep latency (from baseline $1.7(1.4-2.0)$ to $1.1(0.8-1.5$ at visit $2, p=0.002)$ and sleep disturbance (from baseline $1.7(1.4-2.0)$ to 1.2 $(0.9-1.6)$ at visit $2, p=0.013)$ components improved significantly from baseline to visit 2 (Table 7).

\section{Sleep quality with respect to DASS-21 scores}

Good sleep quality was noted at visit 1, visit 2 and visit 3 $34.3,40.0$ and $57.1 \%$ of patients with normal depression scores at visit 1 , in $38.7,45.5$ and $50.0 \%$ of patients with normal anxiety scores at visit 1, and in 33.3, 46.2 and $60.0 \%$ of patients with normal stress scores at visit 1 , respectively (Table 8).

\section{Adverse events and treatment alterations under OnabotA therapy}

OnabotA therapy was associated with minor and temporary side effects (e.g., asymmetry of the position of the eyebrows and neck ache) in some patients. In one patient who has a very thin cervical region, dysphagia and difficulty in swallowing appeared while regressed after the third week of therapy. Treatment was continued in this patient with omission of further injections to the cervical area.

Treatment alterations included discontinuation of OnabotA therapy $(n=2)$, addition of antiepileptic $(n=3)$ or SSRI $(n=9)$ medications and discontinuation of ongoing antiepileptic $(n=3)$ or SSRI $(n=1)$ medications.

\section{Discussion}

Our findings revealed that administration of four OnabotA injection series over 48 weeks in chronic migraineurs was associated with a significant improvement in all migraine parameters including headache frequency and severity, number of analgesics used and MIDAS scores, while no significant change from baseline was noted in overall sleep quality and prevalence of negative emotional states. Patients without negative emotional states at baseline showed improved sleep quality throughout the study. 
Table 2 Overall headache frequency and severity, analgesic use and MIDAS scores

\begin{tabular}{lllll}
\hline & Headache frequency & Headache severity & Number of analgesics & \multicolumn{1}{c}{ MIDAS score } \\
& Median (IQR) & Median (IQR) & Median (IQR) & $57.0(35.5-75.0)$ \\
\hline Visit 1 $(n=185)$ & $15.0(12.0-25.0)$ & $8.0(7.0-9.0)$ & $20.0(15.0-30.0)$ & $10.5(1.5-23.0)$ \\
Visit 2 $(n=89)$ & $5.0(3.0-10.0)$ & $7.0(5.0-8.0)$ & $5.0(2.0-10.0)$ & $9.0(3.0-24.0)$ \\
Visit 3 $(n=55)$ & $5.0(2.0-10.0)$ & $6.0(5.0-7.0)$ & $4.0(1.0-10.0)$ & $6.0(2.0-10.0)$ \\
Visit 4 $(n=31)$ & $4.0(1.0-9.0)$ & $6.0(5.0-8.0)$ & $4.0(1.0-10.0)$ & $10.0(2.0-15.0)$ \\
Visit 5 $(n=19)$ & $5.0(2.0-10.0)$ & $7.0(5.0-7.0)$ & $5.5(2.0-10.0)$ & \\
\hline
\end{tabular}

$I Q R$ inter-quartile range, $n$ patient count without missing data

Significant reduction in monthly headache frequency, headache severity, number of analgesics used and MIDAS scores in our cohort support the efficacy of OnabotA in reduction of the frequency, intensity, and duration of chronic migraines as well as decreasing medication overuse among CM patients who failed on traditional preventive therapies [22, 25-27, 42-44].

Reduction in MIDAS scores, indicating lesser amount of lost work and personal time due to migraine [6], after OnabotA therapy in our cohort seems notable given that a day lived with severe migraine is considered to be as disabling as a day lived with dementia, quadriplegia or acute psychosis and more disabling than blindness, paraplegia, angina or rheumatoid arthritis $[4,45,46]$.

$\mathrm{CM}$ has been associated with a high intake of abortive medications with estimated analgesic overuse in $50-80 \%$ of patients with $\mathrm{CM}$ that may lead to the development of medication overuse headache (MOH) [47]. Given the similar rates of medication overuse (76.2\%) in our cohort at baseline, reduction in in number of analgesics used starting from the first injection and consistently throughout the study period emphasizes the potential role of OnabotA therapy in prevention of $\mathrm{MOH}$ via headache episode reduction $[25,42,48-50]$.

In terms of monthly headache frequency, headache severity, number of analgesics used and MIDAS scores our findings support the association of OnabotA therapy with rapid improvement in migraine parameters usually after the first session as reported in past studies [26, 27, 30, 51-53].

The rapid improvement of migraine parameters after OnabotA therapy has been linked to the combined pharmacological and the placebo effect at the beginning of the treatment $[51,52]$, while increased benefit offered via repeated OnabotA injections over time is associated with a prophylactic cumulative effect [31, 54]. Also, patients who respond well to therapy early have been suggested to maintain and continue these reductions over at least 2 years [27, 55-57], while limited data are available on long-term efficacy of OnabotA therapy with evaluation of efficacy only up to1 year in most of clinical trials $[42,44,50]$.
Alike to our findings, use of four OnabotA injections over 48 weeks in $\mathrm{CM}$ patients was reported to be associated with significant improvement in monthly headache days, migraine days and medication days that continued throughout the entire study period [42]. Nonetheless, in a longer-term study with seven OnabotA injections in CM patients, based on a decrease in initial efficacy of OnabotA therapy after the third injection, authors concluded that actual improvement and amelioration of daily headache under OnabotA therapy needs several months to be consolidated [52].

Long-term efficacy of OnabotA in CM patients has recently been evaluated in some studies based on administration of OnabotA therapy for 2 years [25], 4 years [43] and 7-9 injections series $[52,58]$. However, while finding are consistent regarding long-term efficacy of therapy with no serious adverse events in responders, they varied in terms of durability of benefit, non-responder rates and the length and necessity of withdrawal of treatment at scheduled times [25, 43, 52, 58].

Both depression and anxiety have been proposed to be a risk factor for migraine chronification [13, 59, 60], while migraine headache frequency and headache severity were reported to be associated with higher rate of depression and anxiety disorders $[4,5,14,61]$. Accordingly, identification of abnormal scores for depression, anxiety and stress in almost half of patients in our cohort is in line with higher rates of selfreported mood and anxiety disorders in patients with $\mathrm{CM}$ as compared with general population and EM patients $[4,5,13,14]$ with more than $40.0 \%$ of $\mathrm{CM}$ patients to meet criteria for moderate to severe anxiety and depression $[4,13]$.

Reduction in headache frequency via 24-week OnabotA therapy was reported to be associated with reduction in depression (via Beck Depression Inventory-II) and anxiety scores (Generalized Anxiety Disorder-7 scale) in a past among CM patients [62]. In fact, even a direct effect of OnabotA injection in amelioration of depressive symptoms has been suggested that probably occur via the facial feedback mechanism with consideration of OnabotA as a 
Table 3 Change in severity, analgesic use, MIDAS scores and headache frequency at follow-up visits

\begin{tabular}{|c|c|c|c|c|c|}
\hline & & Headache severity & Number of analgesics & MIDAS score & Headache frequency \\
\hline \multirow[t]{2}{*}{ Baseline } & $n$ & 89 & 80 & 66 & 89 \\
\hline & LS mean & 8.1 & 26.9 & 67.3 & 19.5 \\
\hline \multirow[t]{2}{*}{ Week 12} & $n$ & 89 & 80 & 66 & 89 \\
\hline & LS mean $(p)$ & $6.2(<0.001)$ & $7.8(<0.001)$ & $17.4(0.001)$ & $6.8(p<0.001)$ \\
\hline \multirow[t]{2}{*}{ Week 24} & $n$ & 52 & 50 & 47 & 55 \\
\hline & LS mean $(p)$ & $5.8(<0.001)$ & $8.7(<0.001)$ & $15.3(<0.001)$ & $7.5(<0.001)$ \\
\hline \multirow[t]{2}{*}{ Week 36} & $n$ & 31 & 28 & 24 & 30 \\
\hline & LS mean $(p)$ & $5.8(<0.001)$ & $5.1(<0.001)$ & $9.3(<0.001)$ & $5.4(<0.001)$ \\
\hline \multirow[t]{2}{*}{ Week 48} & $n$ & 19 & 18 & 17 & 19 \\
\hline & LS mean (p) & $6.1(0.017)$ & $10.4(0.023)$ & $18.5(<0.001)$ & $8.4(0.002)$ \\
\hline
\end{tabular}

$L S$ mean least square mean, $n$ patient count with valid data at each visit, $P p$ value of repeated measures variance analysis with reference to baseline

safe adjunctive treatment to pharmacotherapy for major depressive disorder [63].

In this regard, it seems notable that despite significant reductions obtained via OnabotA therapy in both monthly headache frequency and headache severity in our cohort, no significant change from baseline occurred in depression, anxiety and stress rates throughout the study.

High rates of negative emotional states regardless of the ongoing OnabotA therapy in our patients seems notable given the impact of psychiatric comorbidities on disease prognosis, treatment, and clinical outcomes and higher prevalence of severe headache-related disability, headache impact and poor quality of life in migraineurs with than without psychiatric comorbidities [11, 13, 64]. Hence our findings emphasize consideration of comorbid psychiatric disorders in diagnostic evaluation and formulation of treatment plan in CM patients, being aware of the likely negative impact of co-morbid psychiatric disorder on treatment outcomes, adherence and quality of life $[5,14,65]$.

Identification of poor sleep quality at baseline in $72.9 \%$ of our patients seems consistent with high prevalence $(30-79 \%)$ of co-morbid poor sleep quality among migraineurs $[20,66-68]$, particularly in those with 8 or more migraine days per month [17]. Higher prevalence of poor sleep quality was also noted in patients with migraine compared to those without migraine [17-21], while high migraine frequency was shown to correlate with poor sleep quality and a higher prevalence of poor sleepers in chronic migraineurs [21].

In a past study on the effects of OnabotA on jaw motor events during sleep in sleep bruxism patients, no significant change from baseline was noted in usual sleep variables such as sleep efficiency, arousal index, sleep stages, or awakenings per hour during follow-up recordings [69].

Similarly, our findings revealed no direct effect of OnabotA injection on overall sleep quality at week 12 and week 24, while significant improvement in subjective sleep quality, sleep latency and sleep disturbance at week 12. This seems notable given the reported association of higher migraine frequency with higher scores for certain domains of PSQI such as "cannot get to sleep within 30 minutes," "wake up in the middle of the night or early morning," and "bad dreams" among migraineurs [21].

Sleep-related migraine is considered to be associated with a more severe and disabling clinical course given the increased mean attack severity and monthly use of

Table 4 DASS-21 anxiety, depression and stress scores at study visits

\begin{tabular}{|c|c|c|c|c|c|c|c|c|c|c|c|c|}
\hline \multirow[b]{2}{*}{ Severity } & \multicolumn{4}{|c|}{ DASS-21-Depression score, n (\%) } & \multicolumn{4}{|c|}{ DASS-21-Anxiety score, n (\%) } & \multicolumn{4}{|c|}{ DASS-21-Stress score, n (\%) } \\
\hline & Visit 1 & Visit 2 & Visit 3 & Visit 4 & Visit 1 & Visit 2 & Visit 3 & Visit 4 & Visit 1 & Visit 2 & Visit 3 & Visit 4 \\
\hline Normal & $51(60.0)$ & $13(52.0)$ & $9(60.0)$ & $4(57.1)$ & $48(56.5)$ & $17(51.5)$ & $7(41.2)$ & $4(57.1)$ & $44(51.8)$ & $18(54.5)$ & $5(29.4)$ & $3(42.9)$ \\
\hline Mild & $10(11.8)$ & $6(24.0)$ & $2(13.3)$ & $0(0)$ & $9(10.6)$ & $5(15.2)$ & $3(17.6)$ & $1(14.3)$ & $14(16.5)$ & $6(18.2)$ & $5(29.4)$ & $1(14.3)$ \\
\hline Moderate & $15(17.6)$ & $2(8.0)$ & $3(20.0)$ & $2(28.6)$ & $13(15.3)$ & $5(15.2)$ & $6(35.3)$ & $1(14.3)$ & $16(18.8)$ & $5(15.2)$ & $6(35.3)$ & $2(28.6)$ \\
\hline Severe & $6(7.1)$ & $3(12.0)$ & $1(6.7)$ & $0(0)$ & $10(11.8)$ & $4(12.1)$ & $0(0)$ & $0(0)$ & $7(8.2)$ & $4(12.1)$ & $1(5.9)$ & $1(14.3)$ \\
\hline Extremely severe & $3(3.5)$ & $1(4.0)$ & $0(0)$ & $1(14.3)$ & $5(5.9)$ & $2(6.1)$ & $1(5.9)$ & $1(14.3)$ & $4(4.7)$ & $0(0)$ & $0(0)$ & $0(0)$ \\
\hline Total & $85(100)$ & $25(100)$ & 15 (100) & $7(100)$ & 85 (100) & 33 (100) & $17(100)$ & $7(100)$ & 85 (100) & 33 (100) & $17(100)$ & $7(100)$ \\
\hline
\end{tabular}


Table 5 Change in DASS-21 anxiety, depression and stress scores from baseline at study visits

\begin{tabular}{|c|c|c|c|c|c|c|}
\hline \multirow{2}{*}{$\begin{array}{l}\text { Severity, n (\%) } \\
\text { DASS-21-Depression score }\end{array}$} & \multicolumn{2}{|c|}{ Change at visit 2} & \multicolumn{2}{|c|}{ Change at visit 3} & \multicolumn{2}{|c|}{ Change at visit 4} \\
\hline & Visit 1 & Visit 2 & Visit 1 & Visit 3 & Visit 1 & Visit 4 \\
\hline Normal & $14(56.0)$ & $13(52.0)$ & $8(53.3)$ & $9(60.0)$ & $4(57.1)$ & $4(57.1)$ \\
\hline Abnormal & $11(44.0)$ & $12(48.0)$ & $7(46.7)$ & $6(40.0)$ & $3(42.9)$ & $3(42.9)$ \\
\hline Total & $25(100)$ & $25(100)$ & $15(100)$ & $15(100)$ & $7(100)$ & $7(100)$ \\
\hline$P$ value ${ }^{a}$ & 1.000 & & 1.000 & & 1.000 & \\
\hline DASS-21-Anxiety score & Visit 1 & Visit 2 & Visit 1 & Visit 3 & Visit 1 & Visit 4 \\
\hline Normal & $18(54.5)$ & $17(51.5)$ & $7(41.2)$ & $7(41.2)$ & $3(42.9)$ & $4(57.1)$ \\
\hline Abnormal & $15(45.5)$ & $16(48.5)$ & $10(58.8)$ & $10(58.8)$ & $4(57.1)$ & $3(42.9)$ \\
\hline Total & $33(100)$ & $33(100)$ & $17(100)$ & $17(100)$ & $7(100)$ & $7(100)$ \\
\hline$P$ value ${ }^{a}$ & 1.000 & & 1.000 & & 1.000 & \\
\hline DASS-21-Stress score & Visit 1 & Visit 2 & Visit 1 & Visit 3 & Visit 1 & Visit 4 \\
\hline Normal & $18(54.5)$ & $18(54.5)$ & $4(23.5)$ & $5(29.4)$ & $3(42.9)$ & $3(42.9)$ \\
\hline Abnormal & $15(45.5)$ & $15(45.5)$ & $13(76.5)$ & $12(70.6)$ & $4(57.1)$ & $4(57.1)$ \\
\hline Total & $33(100)$ & $33(100)$ & $17(100)$ & $17(100)$ & $7(100)$ & $7(100)$ \\
\hline$P$ value $^{\mathrm{a}}$ & 1.000 & & 1.000 & & 1.000 & \\
\hline
\end{tabular}

${ }^{\mathrm{a}} \mathrm{McNemar}$ test Comparisons for visit 5 is not performed due to small number patients with valid data

symptomatic drugs in patients with than without sleep related migraine despite similar monthly headache frequency [70].

Although data on sleep quality are available for only two OnabotA injections in our cohort, given that patients without negative emotional states at baseline showed improved sleep quality throughout the study, maintenance of co-morbid negative emotional states throughout the study seems to be associated with lack of improvement in overall sleep quality, despite significantly decreased migraine frequency.

Nonetheless, it should also be noted that while the presence of negative emotional states such as depression was reported to be reciprocally associated with poor sleep quality $[66,71]$ and migraine history and comorbid anxiety and depression were shown as predictors of sleep quality [20] in some studies, poor sleep quality was shown to be associated uniquely with migraine itself, regardless of comorbid depression, anxiety or sleep disorders in other studies, particularly among EM patients $[17,44,72,73]$.

Certain limitations to this study should be considered. First, due to observational nature, non-randomized allocation and thereby the likelihood of main selection bias and confounding is possible. Second, although provide data on real-life clinical practice, potential lack of generalizability seems another important limitation due to single-center design of the study. Third, lack of intervention considering timing and number of follow up visits in accordance with the observational nature caused

Table 6 Overall PSQI scores at study visits

\begin{tabular}{|c|c|c|c|c|c|c|c|c|c|c|}
\hline & \multirow{3}{*}{$\begin{array}{l}\text { Global } \\
\text { score } \\
\text { Median (IQR) }\end{array}$} & \multirow{2}{*}{\multicolumn{2}{|c|}{$\begin{array}{l}\text { Sleep } \\
\text { quality, n(\%) }\end{array}$}} & \multicolumn{7}{|c|}{ Component scores } \\
\hline & & & & \multirow{2}{*}{$\begin{array}{l}\text { Subjective } \\
\text { sleep quality } \\
\text { Median } \\
\text { (IQR) }\end{array}$} & \multirow{2}{*}{$\begin{array}{l}\text { Sleep } \\
\text { latency } \\
\text { Median } \\
\text { (IQR) }\end{array}$} & \multirow{2}{*}{$\begin{array}{l}\text { Sleep } \\
\text { duration } \\
\text { Median (IQR) }\end{array}$} & \multirow{2}{*}{$\begin{array}{l}\text { Habitual } \\
\text { sleep efficiency } \\
\text { Median } \\
\text { (IQR) }\end{array}$} & \multirow{2}{*}{$\begin{array}{l}\text { Sleep } \\
\text { disturbances } \\
\text { Median } \\
\text { (IQR) }\end{array}$} & \multirow{2}{*}{$\begin{array}{l}\text { Use of sleep } \\
\text { medications } \\
\text { Median } \\
\text { (IQR) }\end{array}$} & \multirow{2}{*}{$\begin{array}{l}\text { Daytime } \\
\text { dysfunction } \\
\text { Median } \\
\text { (IQR) } \\
\end{array}$} \\
\hline & & Good & Poor & & & & & & & \\
\hline $\begin{array}{l}\text { Visit } 1 \\
(n=59)\end{array}$ & $9.0(5.0-12.0)$ & $16(27.1)$ & $43(72.9)$ & $2.0(1.0-2.0)$ & $1.0(1.0-2.0)$ & $1.0(0.0-2.0)$ & $1.0(0.0-2.0)$ & $2.0(1.0-2.0)$ & $0.0(0.0-1.0)$ & $1.0(0.0-2.0)$ \\
\hline $\begin{array}{l}\text { Visit } 2 \\
(n=28)\end{array}$ & $7.0(3.0-9.5 .0)$ & $11(39.3)$ & $17(60.7)$ & $1.0(1.0-2.0)$ & $1.0(1.0-2.0)$ & $1.0(0.0-2.0)$ & $0.5(0.0-2.0)$ & $1.0(1.0-2.0)$ & $0.0(0.0-1.0)$ & $1.0(0.0-2.0)$ \\
\hline $\begin{array}{l}\text { Visit } 3 \\
(n=14)\end{array}$ & $10.0(5.0-15.0)$ & $4(28.6)$ & $10(71.4)$ & $2.0(1.0-2.0)$ & $2.0(0.0-2.0)$ & $2.0(1.0-3.0)$ & $1.5(1.0-2.0)$ & $2.0(1.0-2.0)$ & $0.0(0.0-0.0)$ & $2.0(0.0-2.0)$ \\
\hline $\begin{array}{l}\text { Visit } 4 \\
(n=7)\end{array}$ & $8.0(7.0-15.0)$ & $1(14.3)$ & $6(85.7)$ & $1.0(1.0-2.0)$ & $1.0(0.0-2.0)$ & $2.0(1.0-3.0)$ & $2.0(1.0-3.0)$ & $1.0(1.0-2.0)$ & $0.0(0.0-2.0)$ & $2.0(1.0-2.0)$ \\
\hline $\begin{array}{l}\text { Visit } 5 \\
(n=3)\end{array}$ & $4.0(1.0-7.0)$ & $2(66.7)$ & $1(33.3)$ & $1.0(0.0-1.0)$ & $0.0(0.0-1.0)$ & $0.0(0.0-1.0)$ & $0.0(0.0-1.0)$ & $1.0(1.0-2.0)$ & $0.0(0.0-0.0)$ & $1.0(0.0-2.0)$ \\
\hline
\end{tabular}


Table 7 Change in PSQI scores at follow up visits

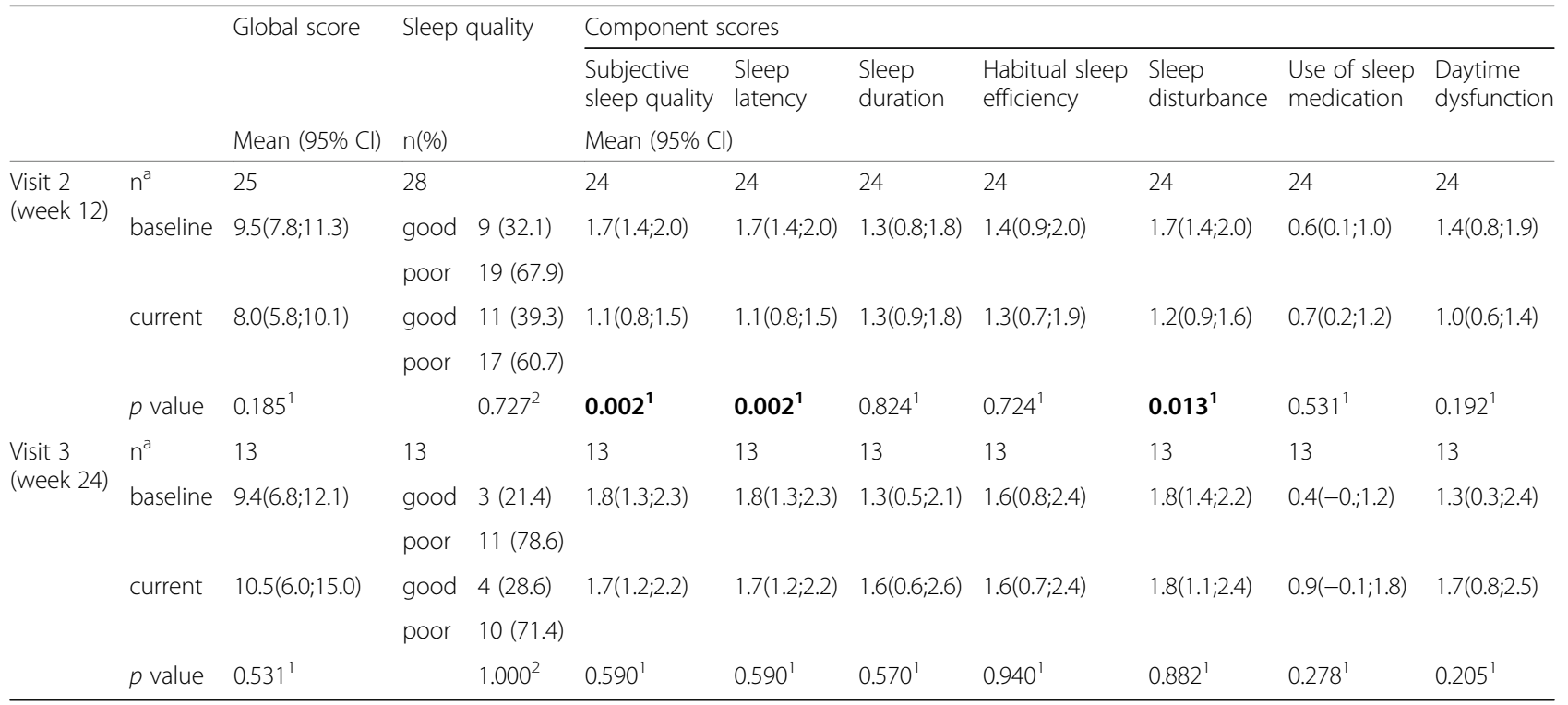

Cl confidence interval

${ }^{a}$ number of patients without missing data (data available for both baseline and the specific follow up visit)

${ }^{1}$ Repeated measures variance analysis, ${ }^{2}$ McNemar test. Comparisons for visit 4 and, visit 5 could not be performed due to small number patients with valid data

Values in bold indicate statistical significance $(p<0.05)$

relatively limited follow-up data and the frequency of patient visits to be not uniform with considerable loss to follow up rate challenging analysis of sleep and mood variables. Fourth, analysis of data on negative emotional states and sleep quality were based on self-report rather than objective measures. However, our analysis was based on use of validated questionnaires along with evidence on high concordance between self-report instruments and clinical diagnosis of psychiatric disorders [13]. Lack of follow up data on sleep quality after second
OnabotA injection, lack of data on inter-individual variations in headache characteristics with likely impact on therapeutic response as well as lack of data on adverse events are other limitations which otherwise would extend the knowledge achieved in the current study.

\section{Conclusions}

In conclusion, our findings in a cohort of chronic migraineurs revealed that OnabotA injection was associated with significant improvement in migraine outcome

Table 8 Sleep quality with respect to DASS-21 anxiety, depression and stress scores

\begin{tabular}{|c|c|c|c|c|c|c|c|c|c|}
\hline & \multicolumn{3}{|l|}{ Visit 1} & \multicolumn{3}{|l|}{ Visit 2} & \multicolumn{3}{|l|}{ Visit 3} \\
\hline & good SQ & poor SQ & Total & good SQ & poor SQ & Total & good SQ & poor SQ & Total \\
\hline & \multicolumn{9}{|l|}{$\mathrm{n}(\%)$} \\
\hline \multicolumn{10}{|c|}{ DASS 21-depression score } \\
\hline Normal & $12(34.3)$ & $23(65.7)$ & $35(100)$ & $4(40.0)$ & $6(60.0)$ & $10(100)$ & $4(57.1)$ & $3(42.9)$ & $7(100)$ \\
\hline Abnormal & $4(16.7)$ & $20(83.3)$ & $24(100)$ & $2(22.2)$ & $7(77.8)$ & $9(100)$ & $0(0)$ & $6(100)$ & $6(100)$ \\
\hline Total & $16(27.1)$ & $43(72.9)$ & $59(100)$ & $6(31.6)$ & $13(68.4)$ & $19(100)$ & $4(30.8)$ & $9(69.2)$ & $13(100)$ \\
\hline \multicolumn{10}{|c|}{ DASS 21-anxiety score } \\
\hline Normal & $12(38.7)$ & $19(61.3)$ & $31(100)$ & $5(45.5)$ & $6(54.5)$ & $11(100)$ & $3(50.0)$ & $3(50.0)$ & $6(100)$ \\
\hline Abnormal & $4(14.3)$ & $24(85.7)$ & $28(100)$ & $3(25.0)$ & $9(75)$ & $12(100)$ & $1(14.3)$ & $6(85.7)$ & $7(100)$ \\
\hline Total & $16(27.1)$ & $43(72.9)$ & $59(100)$ & $8(34.8)$ & $15(65.2)$ & $23(100)$ & $4(30.8)$ & $9(69.2)$ & $13(100)$ \\
\hline \multicolumn{10}{|c|}{ DASS 21-stress score } \\
\hline Normal & $10(33.3)$ & $20(66.7)$ & $30(100)$ & $6(46.2)$ & $7(53.8)$ & $13(100)$ & $3(60.0)$ & $2(40.0)$ & $5(100)$ \\
\hline Abnormal & $6(20.7)$ & $23(79.3)$ & $29(100)$ & $2(20)$ & $8(80)$ & $10(100)$ & $1(12.5)$ & $7(87.5)$ & $8(100)$ \\
\hline Total & $16(27.1)$ & $43(72.9)$ & $59(100)$ & $8(34.8)$ & $15(65.2)$ & $23(100)$ & $4(30.8)$ & $9(69.2)$ & $13(100)$ \\
\hline
\end{tabular}


leading to decrease in headache frequency and severity, number of analgesics used and MIDAS scores. While no significant change was noted in overall sleep quality and prevalence of negative emotional states with OnabotA injections, patients without negative emotional states at baseline showed improved sleep quality throughout the study. There is a need for future larger-scale long-term longitudinal studies addressing the durability as well as predictors of efficacy of OnabotA in CM patients.

\section{Additional file}

Additional file 1: Data set. (XLSX $23.6 \mathrm{~kb})$

\begin{abstract}
Abbreviations
CM: Chronic migraine; DASS-21: Depression, anxiety, and stress scale-21; HRQoL: Health-related quality of life; ICHD: International classification of headache disorders; MIDAS: Migraine disability assessment scale; $\mathrm{MOH}$ : Medication overuse headache; OnabotA: OnabotulinumtoxinA; PREEMPT: Phase 3 research evaluating migraine prophylaxis therapy; PSQI: Pittsburgh sleep quality index; PTSD: Post-traumatic stress disorder
\end{abstract}

\section{Funding}

None.

\section{Availability of data and materials}

The dataset(s) supporting the conclusions of this article is included within the article and its additional file 1.

\section{Authors' contributions}

EIA contributed to conception/design of the research; EIA, PYD, ASK and SK contributed to acquisition, analysis, or interpretation of the data; EIA, PYD, ASK and SK drafted the manuscript; EIA, PYD and ASK critically revised the manuscript; and EIA agrees to be fully accountable for ensuring the integrity and accuracy of the work. All authors read and approved the final manuscript.

\section{Competing interests}

The authors declare that they have no competing interests.

Received: 10 January 2017 Accepted: 13 January 2017

Published online: 17 February 2017

\section{References}

1. International Headache Society. Revised International Headache Society criteria for chronic migraine. Available at: https://www.ichd-3.org/appendix/ a1-migraine/a1-3-chronic-migraine-alternative-criteria Accessed 25 Apr 2016

2. Natoli JL, Manack A, Dean B, Butler Q, Turkel CC, Stovner L, Lipton RB (2010) Global prevalence of chronic migraine: a systematic review. Cephalalgia 30: 599-609

3. Bigal ME, Rapoport AM, Lipton RB, Tepper SJ, Sheftell FD (2003) Assessment of migraine disability using the Migraine Disability Assessment (MIDAS) questionnaire. A comparison of chronic migraine with episodic migraine. Headache 43:336-342

4. Blumenfeld AM, Varon SF, Wilcox TK, Buse DC, Kawata AK, Manack A, Goadsby PJ, Lipton RB (2011) Disability, HRQoL and resource use among chronic and episodic migraineurs: results from the international burden of migraine study (IBMS). Cephalalgia 31:301-315

5. Buse DC, Manack A, Serrano D, Turkel C, Lipton RB (2010) Sociodemographic and comorbidity profiles of chronic migraine and episodic migraine sufferers. J Neurol Neurosurg Psychiatry 81:428-432

6. Stewart WF, Wood GC, Manack A, Varon SF, Buse DC, Lipton RB (2010) Employment and work impact of chronic migraine and episodic migraine. J Occup Environ Med 52:8-14

7. Meletiche DM, Lofland JH, Young WB (2001) Quality of life differences between patients with episodic and transformed migraine. Headache 41: $573-578$
8. Bigal ME, Serrano D, Reed M, Lipton RB (2008) Chronic migraine in the population: burden, diagnosis, and satisfaction with treatment. Neurology 71:559-566

9. Katsarava Z, Buse DC, Manack AN, Lipton RB (2012) Defining the differences between episodic migraine and chronic migraine. Curr Pain Headache Rep 16:86-92

10. Bigal ME, Rapoport AM, Sheftell FD, Tepper SJ, Lipton RB (2004) Transformed migraine and medication overuse in a tertiary headache centre-clinical characteristics and treatment outcomes. Cephalalgia 24:483-490

11. Jette N, Patten S, Williams J, Becker W, Wiebe S (2008) Comorbidity of migraine and psychiatric disorders: a national population-based study. Headache 48:501-516

12. Lanteri-Minet M, Radat F, Chautard M-H, Lucas C (2005) Anxiety and depression associated with migraine: influence on migraine subjects' disability and quality of life, and acute migraine management. Pain 118:319-326

13. Buse DC, Silberstein SD, Manack AN, Papapetropoulos S, Lipton RB (2013) Psychiatric comorbidities of episodic and chronic migraine. J Neurol 260: 1960-1969

14. Zwart JA, Dyb G, Hagen K, Ødegård KJ, Dahl AA, Bovim G, Stovner L (2003) Depression and anxiety disorders associated with headache frequency. The Nord-Trøndelag Health Study. Eur J Neurol 10:147-152

15. Juang KD, Wang SJ, Fuh JL, Lu SR, Su TP (2000) Comorbidity of depressive and anxiety disorders in chronic daily headache and its subtypes. Headache 40:818-823

16. Peterlin BL, Tietjen G, Meng S, Lidicker J, Bigal M (2008) Post-traumatic stress disorder in episodic and chronic migraine. Headache 48:517-522

17. Seidel S, Hartl T, Weber M, Matterey S, Paul A, Riederer F, Gharabaghi M, Wöber-Bingöl C, Wöber C, PAMINA Study Group (2009) Quality of sleep, fatigue and daytime sleepiness in migraine-a controlled study. Cephalalgia 29:662-669

18. Sadeghniiat K, Rajabzadeh A, Ghajarzadeh M, Ghafarpour M (2013) Sleep quality and depression among patients with migraine. Acta Med Iran 51 784-788

19. Morgan I, Eguia F, Gelaye B, Peterlin BL, Tadesse MG, Lemma S, Berhane Y, Williams MA (2015) Sleep disturbances and quality of life in Sub-Saharan African migraineurs. J Headache Pain 16:18

20. Zhu Z, Fan X, Li X, Tan G, Chen L, Zhou J (2013) Prevalence and predictive factors for poor sleep quality among migraineurs in a tertiary hospital headache clinic. Acta Neurol Belg 113:229-235

21. Lin YK, Lin GY, Lee JT, Lee MS, Tsai CK, Hsu YW, Lin YZ, Tsai YC, Yang FC (2016) Associations between sleep quality and migraine frequency: a crosssectional case-control study. Medicine (Baltimore) 95:e3554

22. National Institute of Neurological Disorders and Stroke. Migraine information. Available at: www.ninds.nih.gov/disorders/migraine/migraine. htm. Accessed Apr 252016

23. Dodick DW (2005) Triptan nonresponder studies: implications for clinical practice. Headache 45:156-162

24. Lionetto L, Negro A, Palmisani S, Gentile G, Del Fiore MR, Mercieri M, Simmaco M, Smith T, Al-Kaisy A, Arcioni R, Martelletti P (2012) Emerging treatment for chronic migraine and refractory chronic migraine. Expert Opin Emerg Drugs 17:393-406

25. Negro A, Curto M, Lionetto L, Martelletti P (2015) A two years open-label prospective study of OnabotulinumtoxinA $195 \mathrm{U}$ in medication overuse headache: a real-world experience. J Headache Pain 17:1

26. Rothrock JF (2012) Botox-A for suppression of chronic migraine: commonly asked questions. Headache 52:716-717

27. Sanassi LA (2016) Botulinum toxin: a lift for chronic migraines. JAAPA 29:1-4, Review

28. Aurora SK, Dodick DW, Turkel CC, DeGryse RE, Silberstein SD, Lipton RB, Diener HC, Brin MF, PREEMPT 1 Chronic Migraine Study Group (2010) OnabotulinumtoxinA for treatment of chronic migraine: results from the double-blind, randomized placebo-controlled phase of the PREEMPT 1 trial. Cephalalgia 30:793-803

29. Diener HC, Dodick DW, Aurora SK, Turkel CC, DeGryse RE, Lipton RB, Silberstein SD, Brin MF, PREEMPT 2 Chronic Migraine Study Group (2010) OnabotulinumtoxinA for treatment of chronic migraine: results from the double-blind, randomized, placebo-controlled phase of the PREEMPT 2 trial. Cephalalgia 30:804-814

30. Dodick DW, Turkel CC, DeGryse RE, Aurora SK, Silberstein SD, Lipton RB, Diener HC, Brin MF (2010) OnabotulinumtoxinA for treatment of chronic migraine: pooled results from the double-blind, randomized placebocontrolled phases of the PREEMPT clinical program. Headache 50:921-936 
31. Aurora SK, Dodick DW, Diener HC, DeGryse RE, Turkel CC, Lipton RB, Silberstein SD (2014) OnabotulinumtoxinA for chronic migraine: efficacy, safety, and tolerability in patients who received all five treatment cycles in the PREEMPT clinical program. Acta Neurol Scand 129:61-70

32. Allergan Inc (2013) BOTOX (onabotulinumtoxinA) full prescribing information. Allergan Inc, Irvine

33. Blumenfeld A, Silberstein SD, Dodick DW, Aurora SK, Turkel CC, Binder WJ (2010) Method of injection of onabotulinumtoxinA for chronic migraine: a safe, well-tolerated, and effective treatment paradigm based on the PREEMPT clinical program. Headache 50:1406-1418

34. Sawyer J (2001) Development and testing of the migraine disability assessment (MIDAS) questionnaire to assess headache-related disability. Neurology 15:20-28

35. Ertas M, Siva A, Dalkara T, Uzuner N, Dora B, Inan L, Idiman F, Sarica Y, Selcuki D, Sirin H, Oguzhanoglu A, Irkec C, Ozmenoglu M, Ozbenli T, Ozturk M, Saip S, Neyal M, Zarifoglu M, Turkish MIDAS group (2004) Validity and reliability of the Turkish migraine disability assessment (MIDAS) questionnaire. Headache 15:786-793

36. Lovibond SH, Lovibond PF (1995) Manual for the depression anxiety stress scales, 2nd edn. Psychology Foundation, Sydney

37. Brown TA, Chorpita BF, Korotitsch W, Barlow DH (1997) Psychometric properties of the depression anxiety stress scales (DASS) in clinical samples. Behav Res Ther 35:79-89

38. Antony MM, Bieling PJ, Brian J, Cox BJ, Enns MW, Swinson RP (1998) Psychometric properties of the 42-item and 21-item versions of the depression anxiety stress scales in clinical groups and a community sample. Psychol Assess 10:176-181

39. Hekimoglu L, Altun ZO, Kaya EZ, Bayram N, Bilgel N (2012) Psychometric properties of the Turkish version of the 42 item depression anxiety stress scale (DASS-42) in a clinical sample. Int J Psychiatry Med 44:183-198

40. Buysse DJ, Reynolds CF 3rd, Monk TH, Berman SR, Kupfer DJ (1998) The Pittsburgh sleep quality index: a new instrument for psychiatric practice and research. Psychiatry Res 28:193-213

41. Agargun MY, Kara H, Anlar O (1996) Pittsburgh Uyku kalitesi indeksi'nin gecerliliği ve güvenilirligi. Turk Psikiyatri Derg 7:107-115 [Turkish]

42. Kollewe K, Escher CM, Wulff DU, Fathi D, Paracka L, Mohammadi B, Karst M, Dressler D (2016) Long-term treatment of chronic migraine with OnabotulinumtoxinA: efficacy, quality of life and tolerability in a real-life setting. J Neural Transm (Vienna) 123:533-540

43. Cernuda-Morollón E, Ramón C, Larrosa D, Alvarez R, Riesco N, Pascual J (2015) Long-term experience with onabotulinumtoxinA in the treatment of chronic migraine: what happens after one year? Cephalalgia 35:864-868

44. Jackson JL, Kuriyama A, Hayashino Y (2012) Botulinum toxin A for prophylactic treatment of migraine and tension headaches in adults: a meta-analysis. JAMA 307:1736-1745

45. Harwood RH, Sayer AA, Hirschfeld M (2004) Current and future worldwide prevalence of dependency, its relationship to total population, and dependency ratios. Bull World Health Organ 82:251-258

46. Menken M, Munsat TL, Toole JF (2000) The global burden of disease study: implications for neurology. Arch Neurol 57:418-420

47. Deiner HC, Limmroth V (2004) Medication overuse headache: a worldwide problem. Lancet Neurol 3:475-483

48. Silberstein SD, Blumenfield AM, Cady RK, Turner IM, Lipton RB, Deiner HC, Aurora SK, Sirimanne M, DeGryse RE, Turkel CC, Dodick DW (2013) OnabotulinumtoxinA for treatment of chronic migraine: PREEMPT 24-week pooled subgroup analysis of patients who had acute headache medication overuse at baseline. J Neurol Sci 331:48-56

49. Saper JR, Dodick D, Gladstone JP (2005) Management of chronic daily headache: challenges in clinical practice. Headache 45(Suppl 1):S74-S85, Review

50. Finkel AG (2015) Botulinum toxin and the treatment of headache: a clinical review. Toxicon 107:114-119

51. Negro A, Curto M, Lionetto L, Crialesi D, Martelletti P (2015) OnabotulinumtoxinA $155 \mathrm{U}$ in medication overuse headache: a two years prospective study. Springerplus 4:826

52. Guerzoni S, Pellesi L, Baraldi C, Pini LA (2015) Increased efficacy of regularly repeated cycles with onabotulinumtoxinA in $\mathrm{MOH}$ patients beyond the first year of treatment. J Headache Pain 17:48

53. Demiryurek BE, Ertem DH, Tekin A, Ceylan M, Aras YG, Gungen BD (2016) Effects of onabotulinumtoxinA treatment on efficacy, depression, anxiety, and disability in Turkish patients with chronic migraine. Neurol Sci 37:1779-1784
54. Silberstein SD, Dodick WD, Aurora SK, Dienere H-C, DeGryse RE, Lipton RB, Turkel CC (2015) Per cent of patients with chronic migraine who responded per onabotulinumtoxinA treatment cycle: PREEMPT. J Neurol Neurosurg Psychiatry 86:996-1001

55. Khalil M, Zafar HW, Quarshie V, Ahmed F (2014) Prospective analysis of the use of onabotulinumtoxinA (BOTOX) in the treatment of chronic migraine: real-life data in 254 patients from Hull, UK. J Headache Pain 15:54

56. Lipton RB, Varon SF, Grosberg B, McAllister PJ, Freitag F, Aurora SK, Dodick DW, Silberstein SD, Diener HC, DeGryse RE, Nolan ME, Turkel CC (2011) OnabotulinumtoxinA improves quality of life and reduces impact of chronic migraine. Neurology 77:1465-1472

57. Baney J (2011) How effective is long-term use of botox for chronic migraine? Neurol Rev 19:18A

58. Blumenfeld AM, Inocelda A, Purdy C, Dalfonso L, Magar R (2015) The durability of onabotulinumtoxinA for the treatment of chronic migraine: CLARITY Pilot Study. Toxicon 93(Suppl):S11

59. Bigal M (2009) Migraine chronification-concept and risk factors. Discov Med 8:145-150

60. Ashina S, Buse DC, Maizels M, Manack A, Serrrano D, Turkel CC, Lipton RB (2010) Self-reported anxiety as a risk factor for migraine chronification: results from the American Migraine Prevalence and Prevention (AMPP) study. Headache 50(Suppl 1):4

61. Fishbain DA, Cutler R, Rosomoff HL, Rosomoff RS (1997) Chronic painassociated depression: antecendent or consequence of chronic pain? A review. Clin J Pain 13:116-137

62. Boudreau GP, Grosberg BM, McAllister PJ, Lipton RB, Buse DC (2015) Prophylactic onabotulinumtoxinA in patients with chronic migraine and comorbid depression: an open-label, multicenter, pilot study of efficacy, safety and effect on headache-related disability, depression, and anxiety. Int J Gen Med 8:79-86

63. Parsaik AK, Mascarenhas SS, Hashmi A, Prokop LJ, John V, Okusaga O, Singh B (2016) Role of botulinum toxin in depression. J Psychiatr Pract 22:99-110

64. Silberstein SD, Dodick D, Freitag F, Pearlman SH, Hahn SR, Scher Al, Lipton RB (2007) Pharmacological approaches to managing migraine and associated comorbidities — clinical considerations for monotherapy versus polytherapy. Headache 47:585-599

65. Blier P, Abbott FV (2001) Putative mechanisms of action of antidepressant drugs in affective and anxiety disorders and pain. J Psychiatry Neurosci 26 $37-43$

66. Ghajarzadeh M, Jalilian R, Togha M, Azimi A, Hosseini P, Babaei N (2014) Depression, poor sleep, and sexual dysfunction in migraineurs women. Int J Prev Med 5:1113-1118

67. Kelman L, Rains JC (2005) Headache and sleep: examination of sleep patterns and complaints in a large clinical sample of migraineurs. Headache 45:904-910

68. Alberti A (2006) Headache and sleep. Sleep Med Rev 10:431-437

69. Shim YJ, Lee MK, Kato T, Park HU, Heo K, Kim ST (2014) Effects of botulinum toxin on jaw motor events during sleep in sleep bruxism patients: a polysomnographic evaluation. J Clin Sleep Med 10:291-298

70. Gori S, Lucchesi C, Baldacci F, Bonuccelli U (2015) Preferential occurrence of attacks during night sleep and/or upon awakening negatively affects migraine clinical presentation. Funct Neurol 30:119-123

71. Gori S, Morelli N, Maestri M, Fabbrini M, Bonanni E, Murri L (2005) Sleep quality, chronotypes and preferential timing of attacks in migraine without aura. J Headache Pain 6:258-260

72. Gori S, Lucchesi C, Maluccio MR, Morelli N, Maestri M, Bonanni E, Murri L (2012) Inter-critical and critical excessive daily sleepiness in episodic migraine patients. Neurol Sci 33:1133-1136

73. Walters AB, Hamer JD, Smitherman TA (2014) Sleep disturbance and affective comorbidity among episodic migraineurs. Headache 54:116-124 